\title{
"Nossa História é OUTRA COMO É OUTRA NOSSA PROBLEMÁTICA": BEATRIz NAscimento POR SUA OBRA
}

NASCIMENTO, Beatriz. Beatriz Nascimento, quilombola e intelectual. Possibilidades nos dias da destruição. São Paulo: Editora Filhos da África, 2018. 488 p.

livro Beatriz Nascimento, quilombola e intelectual, organizado e editado pela União dos Coletivos Pan-Africanistas (UCPA), reúne o conjunto mais completo de escritos da historiadora e militante Beatriz Nascimento, entre já publicados e inéditos. ${ }^{1}$ A publicação chega em boa hora, atendendo a uma demanda crescente por parte de ativistas, estudantes e pesquisadores ávidos

1 Uma primeira coletânea de textos de Beatriz Nascimento, reunindo onze deles, foi organizada por Alex Ratts, Eu sou atlântica. Sobre a trajetória de vida de Beatriz Nascimento, São Paulo: Instituto Kwanza; Imprensa Oficial do Estado, 2006. Uma compilação de textos literários foi organizada e publicada também por Ratts, em parceria com Bethânia Gomes, filha de Beatriz Nascimento, Todas (as) distâncias: poemas, aforismos e ensaios de Beatriz Nascimento, Salvador: Editora Ogum's Toques Negros, 2015. pelo conhecimento e reconhecimento da produção intelectual de negros e negras de diferentes gerações. A iniciativa da UCPA está em consonância com o projeto editorial que informou sua criação, assim como de outras editoras fundadas com o propósito de divulgar autoras e autores negros historicamente preteridos pelos grupos editoriais consolidados. A novidade, diga-se de passagem, são iniciativas semelhantes vindas de grandes editoras que, apenas recentemente, têm incluído em seus catálogos negros notáveis no campo das Ciências Sociais e da Literatura. Os organizadores e editores da UCPA têm seus próprios objetivos e público alvo, deixando explícito no primeiro texto de apresentação (orelha do livro) 
sua destinação última: “Quilombola e intelectual: possibilidade nos dias da destruição foi o título mais apropriado para sacramentar na consciência do povo preto a personalidade e a obra desta africana em diáspora: Maria Beatriz Nascimento".

A coletânea, no entanto, também deve despertar a atenção de pesquisadores e estudiosos interessados na história social e intelectual dos movimentos negros nas décadas de 1970 a 1990, notadamente sua influência nos rumos da Historiografia e das Ciências Sociais no Brasil. Não resta dúvida de que os textos de Beatriz Nascimento, reunidos na coletânea em pauta, permitem identificar e entrelaçar experiências pessoais e coletivas, no sentido político e existencial, de uma geração de intelectuais negros e negras que fez dos espaços acadêmicos e da crítica às interpretações "clássicas" sobre o "lugar" e a história do negro na sociedade brasileira uma frente importante de combate ao racismo.

Se é certo que a produção intelectual de Beatriz Nascimento é expressiva de um coletivo, também se devem reconhecer as particularidades, definidas, evidentemente, por suas escolhas políticas e formação acadêmica, mas também por suas experiências de gênero, raça, classe e pessoais-existenciais. Os textos oferecidos ao leitor em parte porque a autora assim o desejou - mostram uma pessoa complexa, uma mulher inteligente, arrojada e inconformada (por vezes desencantada) consigo e com o mundo ao seu redor. Uma vida que extrapola o compreensível intento celebrativo da publicação. Assim, ao percorrer os escritos de Beatriz, é possível reconhecer os caminhos e os descaminhos, os anseios e os obstáculos para a realização de um projeto intelectual, político e existencial informado e alimentado por demandas inscritas no seu próprio corpo.

A coletânea reúne 57 textos e um anexo com poesias e aforismos, que juntos somam 18 escritos, além de fotos inéditas e algumas de acesso público. O primeiro escrito foi publicado na Revista de Cultura Vozes, em 1974. O último, sem data, mas provavelmente redigido entre 
os anos de 1990 e 1995, encontra-se no fundo que guarda o acervo pessoal da historiadora, no Arquivo Nacional, no Rio de Janeiro. ${ }^{2}$ Na coletânea estão artigos, ensaios, resenhas e entrevistas concedidas a diferentes veículos de comunicação, na sua maioria publicados tanto em jornais e revistas da grande imprensa como em periódicos alternativos. Mas também há um número menor de publicações em revistas especializadas, capítulos de livros e inéditos diversos, o que inclui anotações manuscritas e datilografadas de notas de pesquisas, trabalhos para disciplinas de pós-graduação e outros registros variados. Os textos são dispostos cronologicamente, o que permite o reconhecimento de estratégias de intervenção e preocupações políticas, assim como de interesses intelectuais e acadêmicos circunscritos a diferentes contextos ou recorrentes ao longo do tempo.

2 Arquivo Nacional (ANRJ), Rio de Janeiro, Maria Beatriz Nascimento (2D) ש. Os escritos inéditos publicados no livro têm origem neste fundo. Os documentos foram doados pela família de Beatriz Nascimento ao ANRJ e disponibilizados para consulta pública em 1999.
Nos anos de 1970, Beatriz publicou em vários veículos de comunicação de massa e jornais mais voltados para o público acadêmico e intelectual. Foram cinco textos no Jornal do Brasil, entre eles duas resenhas e uma carta resposta; um artigo no jornal Última Hora e duas resenhas e um ensaio no tabloide Opinião. No mesmo período, teve um artigo publicado no jornal $O$ Movimento e outro na revista Isto é. Além dessas publicações, concedeu duas entrevistas, uma para a revista Manchete e a segunda para um documentário produzido pela TV Cultura de São Paulo. Na Revista de Cultura Vozes, publicou três textos que, de certo modo, elucidam o foco político e intelectual do conjunto anteriormente relacionado, incluindo a gênese de projetos a serem desenvolvidos no futuro.

Antes de apresentar sucintamente os principais temas dos textos publicados nos anos de 1970, vale a pena trazer algumas palavras sobre o contexto (inclusive em termos pessoais) no qual se insere a dita produção. Este período, que evidencia um investimento notável 
de Beatriz no ativismo por meio de publicações na imprensa, coincide com o final de sua graduação em História na Universidade Federal do Rio de Janeiro (UFRJ), o início da Pós-Graduação na Universidade Federal Fluminense (UFF) e a constituição de uma militância negra pioneira nos meios estudantis universitários do Rio de Janeiro. O Grupo de Trabalho André Rebouças, criado por estudantes da UFF, em 1973, teve entre seus membros e colaboradores, além da própria Beatriz, Marlene Cunha, Andrelino Campos, Eduardo de Oliveira e Oliveira, entre outros.

Os textos publicados naquela década, assim como alguns inéditos escritos no mesmo período, expressam os interesses acadêmicos e os vínculos políticos da historiadora recém-formada. A crítica à falácia da democracia racial e, ao mesmo tempo, a denúncia do racismo “à brasileira” - uma das principais bandeiras do movimento negro no período - é central nas suas intervenções públicas, juntamente com a apresentação de um projeto acadêmico militante de reescrita da História do Brasil por mãos negras. ${ }^{3}$ Além de remeterem aos debates constituintes dos movimentos negros que se apresentam à cena pública nos anos 1970, as suas intervenções também apontam para uma vertente importante que se expressou no Rio de Janeiro, particularmente com a formação do Grupo de Trabalho André Rebouças, acima mencionado. Pensando nestes termos, sua presença na imprensa - com textos direcionados para públicos distintos - faz todo sentido.

"Nossa democracia racial”, nas palavras de Beatriz, legitima "a crença num sistema de relações raciais pacífico” e, ao mesmo tempo, sustenta "mecanismos seletivos [...] [que reduzem] o espaço dedicado ao negro dentro da escala social” (p. 115). Considerando o poder da "crença” e a força dos "mecanismos" que sustentam o racismo no Brasil, o combate deveria ser feito em várias frentes. Era preciso “falar” também para/

3 Amilcar Araújo Pereira, O Mundo Negro: a constituição do movimento negro contemporâneo no Brasil (19701995), Tese (Doutorado em História), Universidade Federal Fluminense, Niterói, 2010, p. 98 ש. 
com/em contraposição àqueles que negavam a existência do racismo no Brasil - eterno fardo do intelectual negro nacional -, estando entre esses, talvez, os leitores do Jornal do Brasil e do diário Última Hora. Em consonância com essa estratégia, as resenhas publicadas nos mesmos periódicos apresentavam uma jovem historiadora propondo uma revisão da história do Brasil na perspectiva dos negros. O que também não deixa de ser um enfrentamento da lógica que apenas delimita os negros - e mais ainda as negras - a lugares de escrita socialmente marginais e periféricos.

Mas a tarefa não terminava aí. Também era preciso esclarecer os "aliados da esquerda", dentro e fora da academia (provavelmente leitores do Opinião e da Revista de Cultura Vozes), que com suas teorias de determinação econômica e de classe, "não esquecendo da herança escravagista”, manifestavam indisfarçável incômodo com o chamado “divisionismo" promovido pelos movimentos negros e, ao mesmo tempo, endossavam acriticamente "o mito das três raças formadoras" e das contribuições culturais do negro à nacionalidade (pp. 53-54). Era preciso dizer que o "enegrecimento" cultural da classe média, cantado em verso e prosa, não aliviava em nada a vida dos negros (p. 48). Essa era a mensagem! É ilustrativo desse empreendimento a certeira e ácida resenha do filme Xica da Silva, de Cacá Diegues, que, para Beatriz, "em termos da crítica das relações raciais no Brasil, nos remete à Idade da Pedra”. Se fosse nos dias atuais, poderíamos dizer que Beatriz “cancelou” Diegues expondo sua "branquitude”, ou seja, sua leitura naturalizada do "Brasil visto da Casa Grande”. ${ }^{4}$ Num outro campo “aliado", mais especificamente nos diálogos com os acadêmicos, vale a pena se debruçar sobre o debate com a plateia durante a conferência de Beatriz na Quinzena do Negro, na Universidade de São Paulo (USP), organizada por Eduardo de Oliveira e Oliveira, entre os dias 22 de maio e 8 de junho de 1977. 5 Uma saraivada de balas de ambos os lados!

\footnotetext{
4 “A senzala vista da Casa Grande” (1976), pp. 89-96.

5 "Historiografia do Quilombo. Conferência na Quinzena do Negro na USP” (1977), pp. 125-165.
} 
A busca dos leitores hipotéticos dos textos publicados nos anos de 1970 não pode ignorar, evidentemente, a militância negra e antirracista, principalmente aquela reunida nos coletivos nos quais Beatriz teve participação ativa, como o Centro de Estudos Afro-Asiáticos da Universidade Cândido Mendes e o já referido Grupo de Trabalho André Rebouças da UFF, entre os interlocutores privilegiados dos textos publicados naquele momento (p. 249). "Por uma história do homem negro”, publicado em 1974 na Revista de Cultura Vozes, foi "o primeiro texto discutido nas reuniões do CEAA” (p. 30), segundo a introdução de Raquel Barreto à coletânea. Também é o primeiro onde aparece a formulação do que podemos chamar de uma agenda política e intelectual que vai orientar as escolhas intelectuais de Beatriz Nascimento e, talvez, de outros da sua geração e do seu meio. ${ }^{6}$ O artigo em questão critica o status quo acadêmico, "aqueles

6 Sobre a trajetória de Eduardo Oliveira e Oliveira, por exemplo, ver Rafael Trapp, O Elefante Negro. Eduardo de Oliveira e Oliveira. Raça e pensamento social no Brasil, São Paulo: Alameda, 2020. que veem a História apenas como ciência” e que “abominam a realidade racial por comodismo, medo, ou mesmo racismo”, responsável pela produção de conhecimentos fragmentados e preconceituosos sobre o negro (pp. 43, 45). Em contraposição a esse estado de coisas, reivindica "uma história do homem negro" produzida por mãos negras, pois "nossa história é outra, assim como é outra nossa problemática. [...] Não aceito mais nenhuma forma de paternalismo, especialmente intelectual” (p. 49).

Uma das ideias centrais dessa agenda de pesquisa, retomada por Beatriz em vários textos e entrevistas, é a reivindicação de uma história do negro além da escravidão, uma história negra da e na liberdade. O que sugere prováveis impactos deste debate, interno ao movimento negro, na emergência dos estudos sobre o pós-abolição. Mas Beatriz também reivindicava uma história da liberdade negra ainda no contexto da escravidão. O potencial dos quilombos para este empreendimento foi reconhecido por Beatriz, como ela mesma confessa, 
ainda durante seu estágio enquanto pesquisadora no Arquivo Nacional, sob orientação do historiador José Honório Rodrigues (p. 129). Seus primeiros escritos sobre o tema datam da segunda metade dos anos $1970 .^{7}$ No final desse período, Beatriz deixou de lado a arena dos periódicos e decidiu investir na carreira acadêmica. Em 1979, seria aprovada no Mestrado em História da UFF. Afirmou tempos depois que já tinha o projeto em andamento quando do seu ingresso (p. 361). Os inéditos e publicações dos anos anteriores atestam essa afirmação.

É importante notar que esses primeiros trabalhos não apresentam propriamente resultados de pesquisa em fontes primárias, embora ela mencione o contato com estes materiais no Arquivo Nacional (p. 129). Os textos demonstram um esforço de leitura crítica da bibliografia e algumas hipóteses e enquadramentos - por

7 "Quilombos, mudança social e conservantismo” (1976), pp. 66-79; “Zumbi de N'Gola Djanga ou de Angola Pequena ou do Quilombo dos Palmares” (1976), pp. 104-111; “Quilombo: em Palmares, na Favela, no Carnaval” (1977) pp. 189-194; “O Quilombo do Jabaquara” (1979), pp. 166-168. vezes generalizantes, considerando as reduzidas evidências disponíveis - para uma interpretação revisionista da historiografia dos quilombos. A lista de referências bibliográficas é composta por especialistas tais como Edison Carneiro, Arthur Ramos, Décio Freitas e Clóvis Moura, nesta sequência de importância. De forma bastante resumida, é possível dizer que são três seus principais argumentos. $\mathrm{O}$ entendimento do quilombo a partir da chave da reação contra-aculturativa (em concordância com Ramos e principalmente Carneiro), rompe com uma visão idealizada de luta pela liberdade e reconhece os quilombos como iniciativas de rejeição à sociedade colonial e como projetos alternativos de organização social (pp. 69, 105). Nesse sentido, a fuga para o quilombo não significava ausência de atributos revolucionários, mas um projeto político original (crítica a Décio Freitas). O segundo ponto é a valorização da “paz quilombola”, em detrimento do caráter rebelde e militarista do quilombo (crítica a Clóvis Moura), o que reforçaria o argumento deste como 
sociedade alternativa (pp. 75, 76). $\mathrm{O}$ terceiro argumento ressalta a continuidade ("conservantismo") dos quilombos além do período escravagista. Afinal, interessava a ela a história negra da liberdade. A busca dessa continuidade é proposta em dois sentidos: o reconhecimento de comunidades remanescentes de antigos quilombos em vários estados e localidades do Brasil; a tradição quilombola de formação de comunidades alternativas multirraciais como parâmetro para a ação política e referência para uma "verdadeira democracia racial" (pp. 134, 192).

O objetivo do projeto de Mestrado, na sua primeira formulação, foi “estabelecer uma linha de continuidade histórica entre os 'quilombos', como forma de resistência organizada dos negros nos séculos de dominação escravista e suas formas atuais de resistência” (p. 211). Além da longa duração, a pesquisa não tinha recorte espacial preciso e o levantamento das fontes (escritas e orais) não especificava a natureza nem detalhava a metodologia da investigação. O projeto recebeu financiamento da Fundação
Ford, que recomendou restringir a pesquisa às comunidades remanescentes de quilombos de Minas Gerais, retirando a parte referente a favelas supostamente originadas de antigos quilombos no Rio de Janeiro (pp. 222-226). O interesse pelos referenciais africanos, enfatizados por Edison Carneiro, embora não apareça no projeto de Mestrado, tomam corpo em um levantamento sobre os "remanescentes de quilombos" realizado durante uma viagem a Angola, em 1979. Ao que parece, a viagem foi possível graças aos vínculos de membros do Centro de Estudos Afro-Asiáticos com autoridades e intelectuais angolanos.

O Mestrado foi interrompido, provavelmente em 1985, mas textos escritos entre 1982 e 1990 apresentam resultados parciais das pesquisas realizadas em Minas Gerais, principalmente no quilombo de Carmo da Mata. ${ }^{8}$ A dificuldade de acesso a fontes escritas parece ter sido um dos maiores obstáculos de

8 "Kilombo e memória comunitária" (1982), pp. 253-263. Observem que a autora adota a grafia Kilombo, o que denota ênfase a um possível referencial africano. 
Beatriz para a execução do projeto de pesquisa. De outra parte, suas interpretações a partir dos registros orais - embora partissem de questões interessantíssimas, mesmo para a atualidade - não parecem muito convincentes, nem mesmo para a própria pesquisadora, que reconhece que "o trabalho [...] não pretende estar com a verdade, nem definir uma tese. Estou apenas dizendo: foi o que encontrei” (p. 254). Além das dificuldades de acesso às fontes, o esforço de Beatriz no sentido de lograr uma análise dos referenciais africanos não foi bem sucedido, uma vez que possivelmente não teve acesso a uma bibliografia africanista que desse suporte a seu intento.

No seu conjunto, creio que os escritos publicados e inéditos, datados dos anos de 1980, expõem de modo límpido a tensão entre o projeto ambicioso da historiadora e as dificuldades de execução de uma pesquisa norteada por parâmetros e regras impostas pela academia. Além disso, ou talvez em razão disso, Beatriz passou por momentos de grande instabilidade emocional no período. No depoimento emocionado, publicado no livro Fala Crioulo, de Haroldo Costa, ela própria traduz o momento:

Estou-me analisando não é por diletantismo ou maluquice, talvez nem seja para consertar nada em mim, é possível que esteja para adaptar-me à dualidade de que a sociedade me obriga a aceitar, porque me proíbe ser como eu sou, da mesma forma como faz para outros negros (p. 250).

Por estar se "analisando", Beatriz quis dizer fazendo psicanálise, fique claro.

Muito se discute atualmente sobre as contribuições das pesquisas de Beatriz Nascimento para o estudo dos quilombos. A coletânea oferece uma ótima oportunidade para levar adiante a discussão. Além disso, creio que algumas formulações elaboradas e perseguidas por Beatriz de fato merecem ser revisitadas na sua elaboração e potenciais diálogos com trabalhos posteriores. A atenção à "paz quilombola”, de certo modo, está presente nas primeiras pesquisas de Flávio dos Santos Gomes e outros, sem que os autores estivessem diretamente influenciados pela obra 
da historiadora. Seria interessante investigar a relação - se é que há - entre as proposições de Beatriz Nascimento e esse conjunto de trabalhos. Igualmente, devem ser revisitadas suas pesquisas sobre os remanescentes de quilombos, especialmente a pesquisa com fontes escritas e orais no Rio de Janeiro e Minas Gerais. Evidentemente, o interesse e as pesquisas dela sobre essas comunidades foram contemporâneos dos debates que precederam e informaram o reconhecimento dos quilombos pela Constituição Brasileira de 1988. A partir dos seus escritos - para uma não especialista no tema - não foi possível vislumbrar diálogos com os movimentos negros, parlamentares e pesquisadores que discutiram a matéria durante a constituinte. Por fim, o quilombo como referencial político, para além - ou mesmo na contramão da historiografia - é outro tema que atravessa a militância e a intelectualidade negra há décadas. Abdias do Nascimento reconhece a contribuição de Beatriz na formulação do conceito de quilombismo “como ideia-força, energia que inspira modelos de organização dinâmica desde o século XV". ${ }^{9}$ A pergunta é se não seria interessante tomar para objeto de análise o lugar do quilombo como referencial político no ideário e no ativismo antirracista. Certamente Beatriz Nascimento teria lugar destacado nessa pesquisa.

Os textos publicados em 1990 registram os novos rumos do projeto intelectual, político e pessoal da autora. Sua participação na concepção, roteiro e narração do filme Ori, em parceria com a cineasta Raquel Gerber, de certo modo anuncia uma mudança de rumos que parece ter feito bem a Beatriz. A escolha de novas linguagens e outros referentes teóricos - caminho iniciado com a psicanálise nos anos de 1980 - pavimentaram seu retorno à academia, em 1992, agora no Mestrado em Comunicação Social da UFRJ, sob a orientação de Muniz Sodré. Desgraçadamente, os novos voos de Beatriz foram interrompidos poucos anos depois, em 1995, por sua trágica morte.

9 Abdias do Nascimento, O Quilombismo. documentos de uma militância PanAfricanista,Petrópolis:Vozes, 1980,p. 256. 
Para finalizar, não posso deixar de destacar um tema que, não exatamente pela sua recorrência explícita, merece destaque nesta resenha. A história e a condição da mulher negra atravessam os escritos de Beatriz Nascimento, entre ensaios críticos sobre história e sociedade e reflexões sobre sua própria experiência. Em 1976, ela chama a atenção para as condições particularmente desvantajosas da mulher negra no mercado de trabalho, que "têm menores possibilidades do que qualquer um dos outros grupos”, leia-se: homens brancos, mulheres brancas e homens negros. Em 1990, se debruça sobre a solidão afetiva da mulher negra que ascende socialmente. ${ }^{10}$ Entrementes, mostra interesse em pesquisar mulheres nos quilombos. ${ }^{11}$ E em vários escritos nos deixa ver que sua condição de mulher e negra nunca foi um detalhe menor na sua vida, militância e pesquisas. O caminho biográfico não está vedado ao leitor interessado.

Entretanto, a coletânea também pode ser uma contribuição importante para ir além da recorrente ênfase biográfica heroica - particularmente frequente quando falamos de intelectuais negras - como suporte único e inequívoco da afirmação, da legitimidade e da valorização de suas contribuições intelectuais. Ao contrário, quero crer que a maior deferência que se pode render a um/ uma intelectual é o estudo aprofundado e crítico de sua obra. E este é um dos mais sedutores convites que nos faz a coletânea de textos de Beatriz Nascimento.

\section{Lucilene Reginaldo (D) $\square$}

Universidade Estadual de Campinas

doi: 10.9771/aa.v0i63.44056

\footnotetext{
10 "A mulher negra no mercado de trabalho" (1976), pp. 80-85; e "A mulher negra e o amor” (1990), pp. 353-357.

11 "O papel das mulheres nos quilombos brasileiros” (s.d.), pp. 408-412.
} 